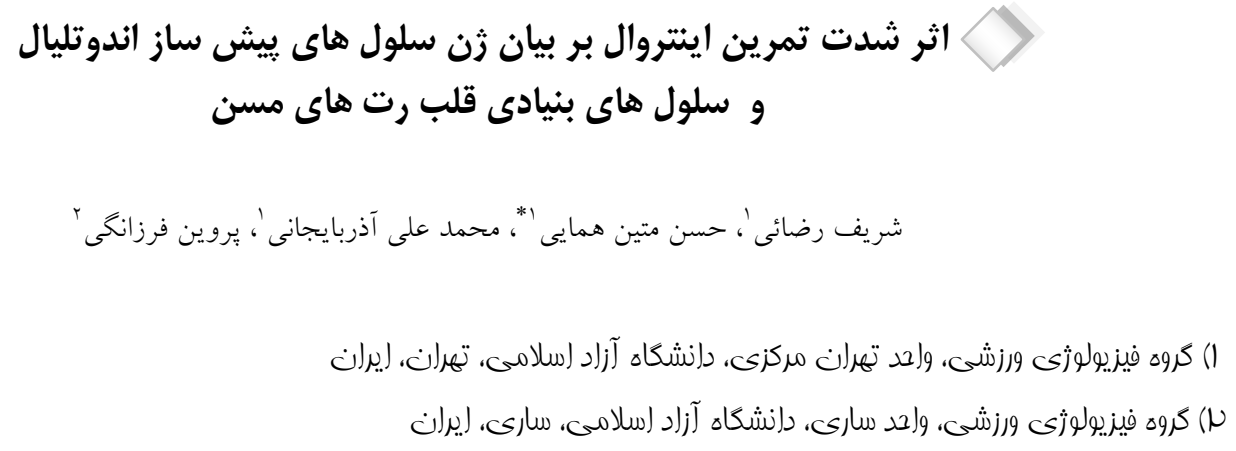

\author{
تاريخ دريافت: ••|\&/\&
}

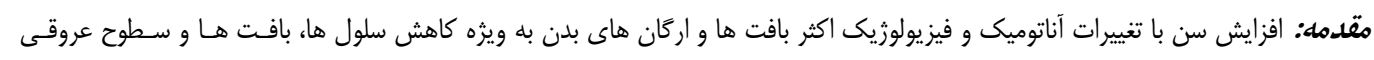

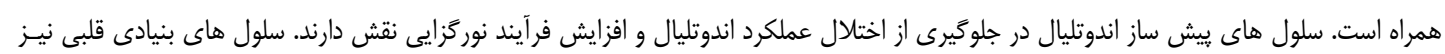

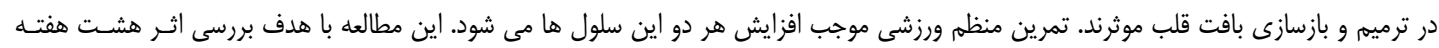

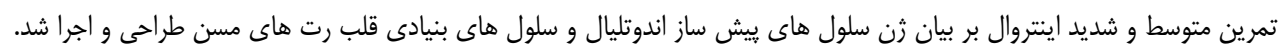

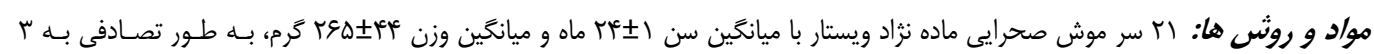

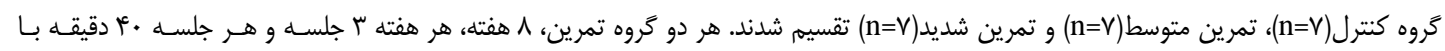

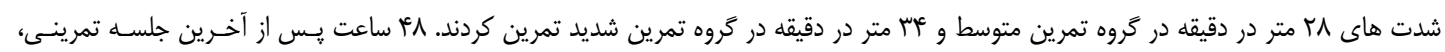

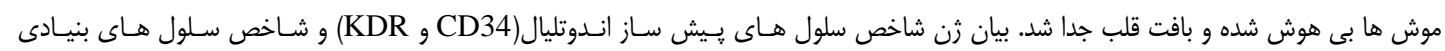

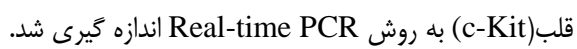

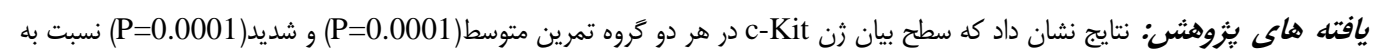

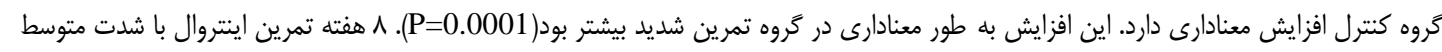

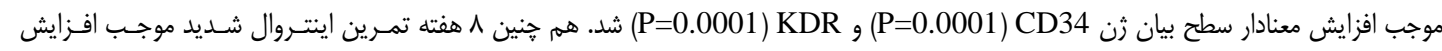

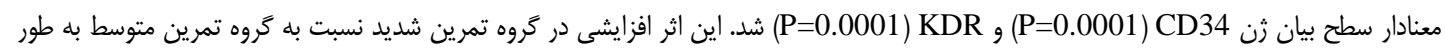

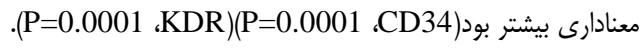

بحث و نتيجه تحيرى: نتايج اين مطالعه نشان داد كه تمرينات منظه هوازى ايتتروال با دو شدت متفاوت سطح بيان زن سلول هاى ييش ساز

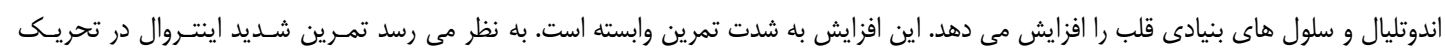

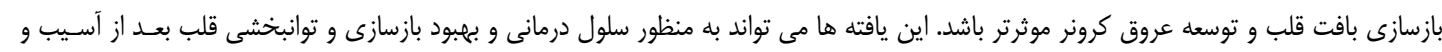
اختلال ميوكارد به ويزه در سالمندان مفيد باشد.

وازه هاى كليدى: تمرين متوسط، تمرين شديد، سلول هاى ييش ساز اندوتليال، سلول هاى بنيادى قلبى، سالمندى

* نويسنده مسئول: گروه فيزيولوزى ورزشى، واحد تهران مركزى، دانشخاه آزاد اسلامى، تهران، ايران

Email:hasanmatinhomaee@gmail.com

Copyright (C) 2018 Journal of Ilam University of Medical Science. This is an open-access article distributed under the terms of the Creative Commons Attribution international 4.0 International License (https://creativecommons.org/licenses/by-nc/4.0/) which permits copy and redistribute the material, in any medium or format, provided the original work is properly cited. 
(تغيير در ديخر سلول ها) دارند(ه). EPCs درون مخزن

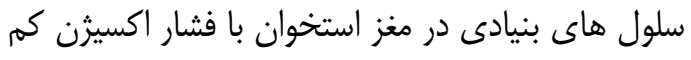
قرار گرفته اند(9) و سطح بالاى فاكتور مشتق از سـلول دئل

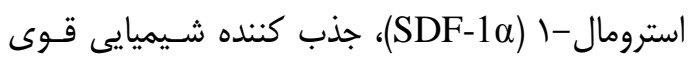

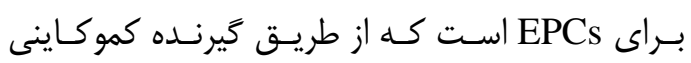
نوع \& (CXCR4) به آن متصل مى شوند( (1).

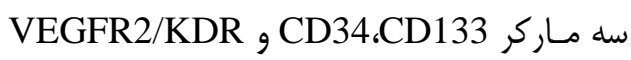
نشان دهنده EPCs اوليه و نارس هستند. سلول هـايى

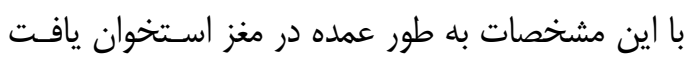

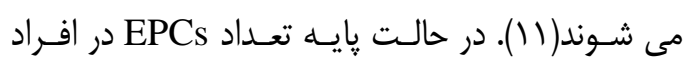
مسن كمتر از جوانان است ولى با تمرين ورزشى، سطح

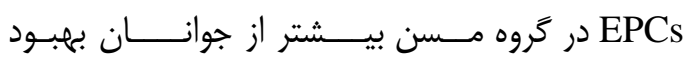

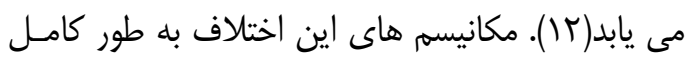

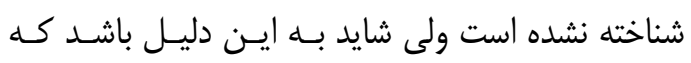
سطح گردش خون گَونه هاى اكسيرن واكنشى (ROS) در افراد مسن بيشتر است، و اين نيز با كاهش محتون أنواى

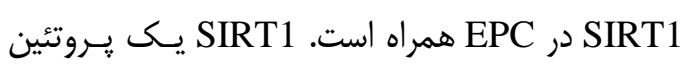
دخيل در ترميم DNA و تنظيم جرخه سلول و و يِ

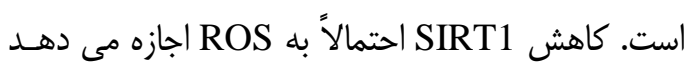
بدون كنترل مداوم آسيب ايجاد كنـد. فعاليـت SIRT1

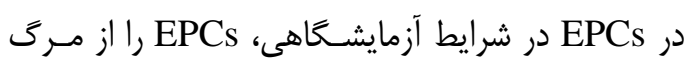

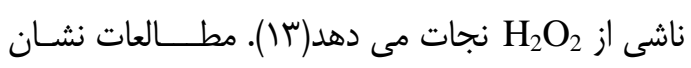

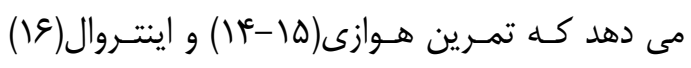

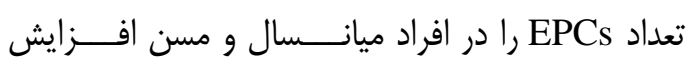
مى دهد. ماركرهاى مختلفـى بـراى توصـيف سـلول هـاى بنيادى قلب(Cardiac Stem Cells: CSCs) اسـتفاده

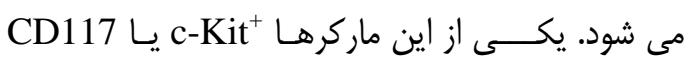

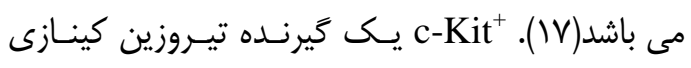

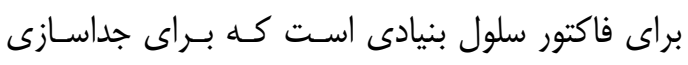
سلول هاى بنــيادى خونساز از مغز اسـتخوان اسـتفاده

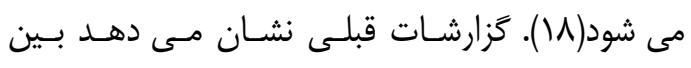

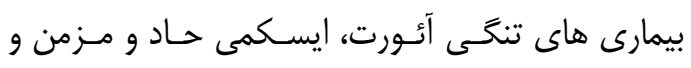

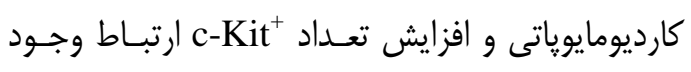

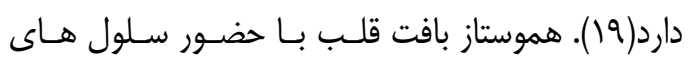

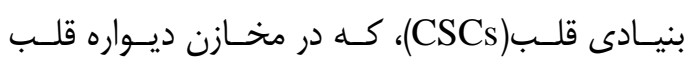

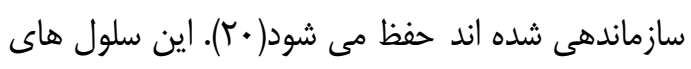

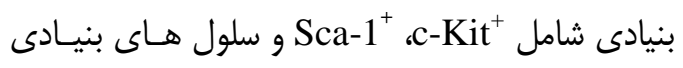

مقدمه

افزايش سن با اختلال عملكرد انسدوتليال، افـزايش

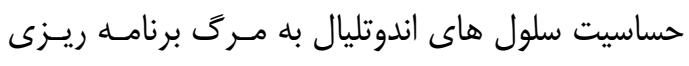

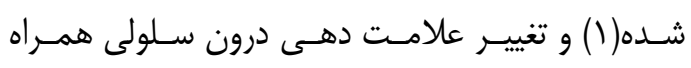

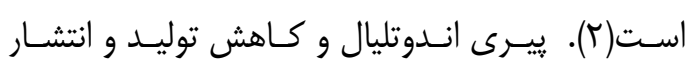
نيتريك اكسايد(NO) با ييبرى عروق در ارتباط اسـت و و

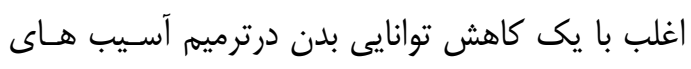

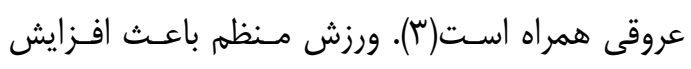
NO

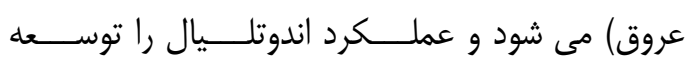

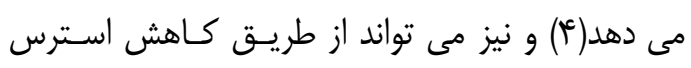

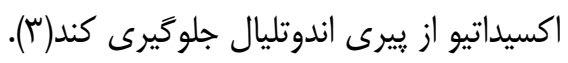
ســانول هـاى يـيش سـاز انـدوتليال( Endotelial (Progenitor Cells: EPCs

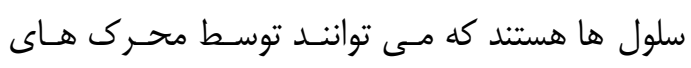

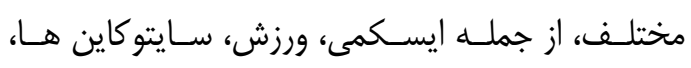

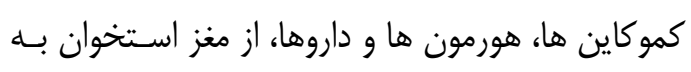

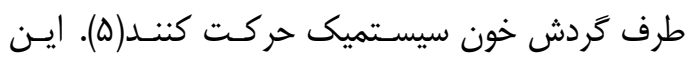

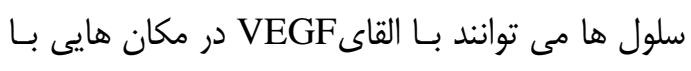

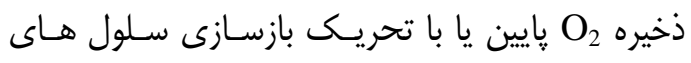

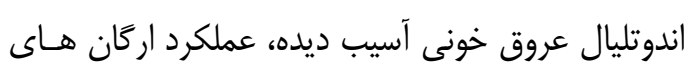

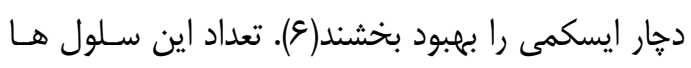

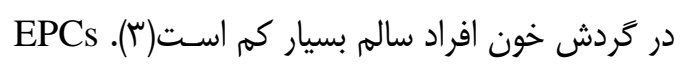

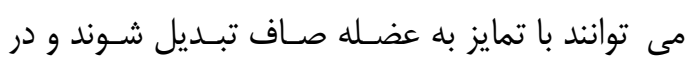

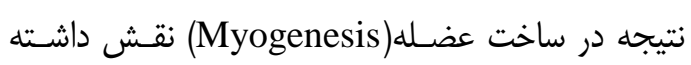

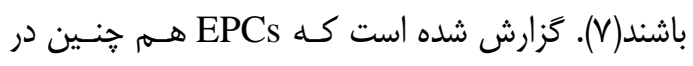

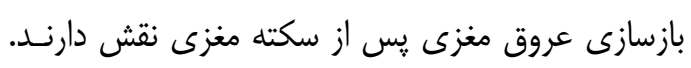

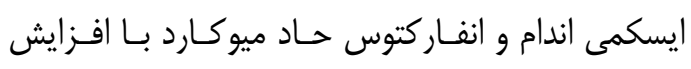

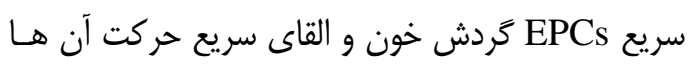

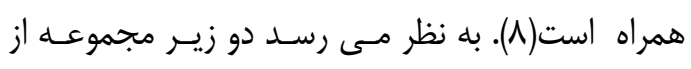

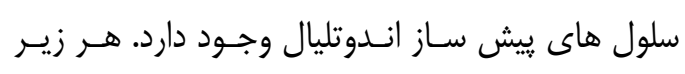
مجموعه نقش متفاوتى را در بازسازى و ترميم عروقى سلى لئس

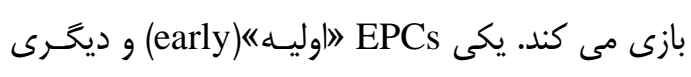

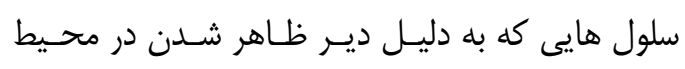

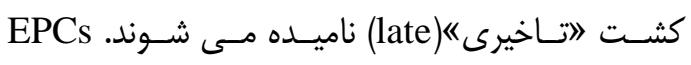

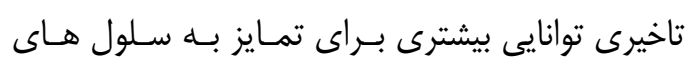

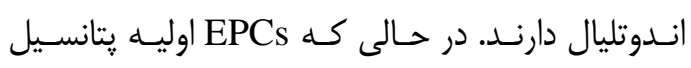
بيشترى براى توسعه ترميم عروق از طريـق يـاراكراين 
مى باشد و موضوعات ناشناخته هم جنان در اين حـوزه

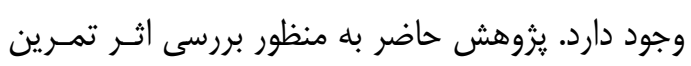

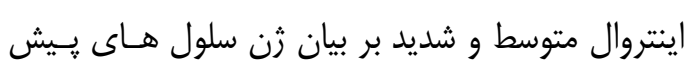

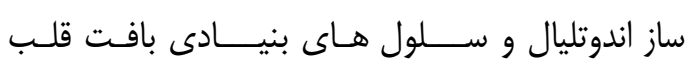
موش هاى مسن طراحى شده است.

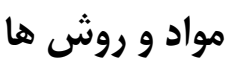

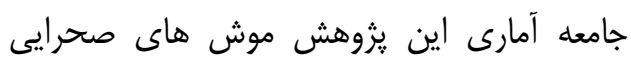

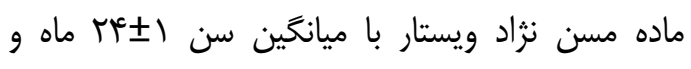

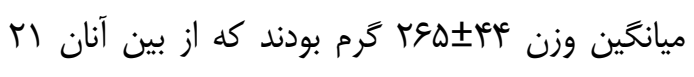
سر موش انتخاب و يس از ورود به محيط يزوهش و و

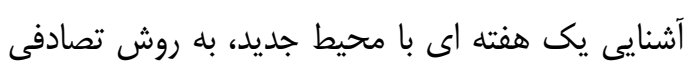

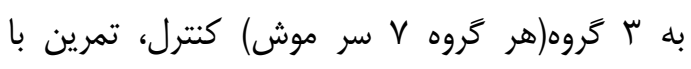

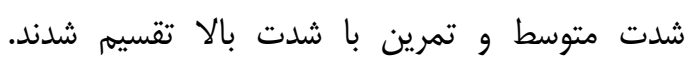

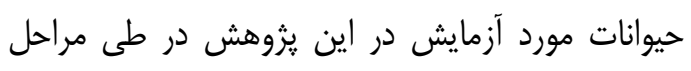

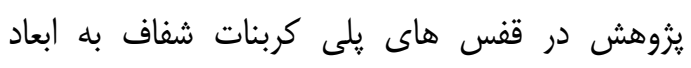

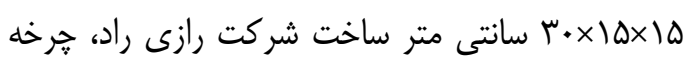

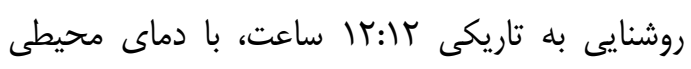

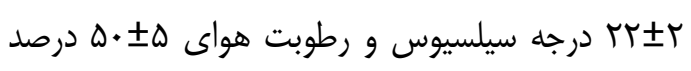

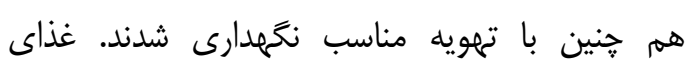
أزمودنى هاى اين يزوهش، بر اساس وزن كشى بـ سه

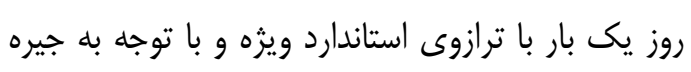

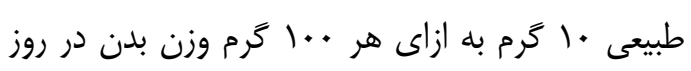

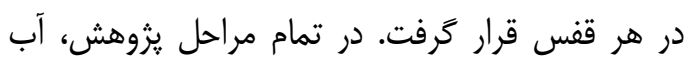

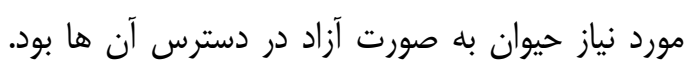

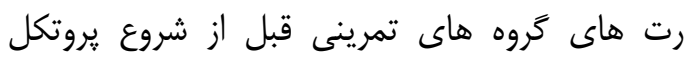

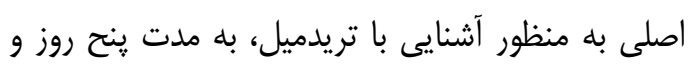

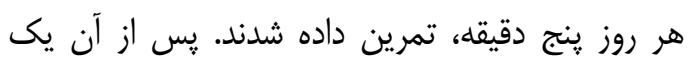

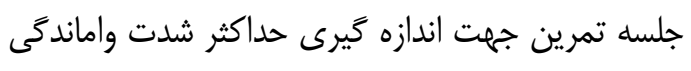

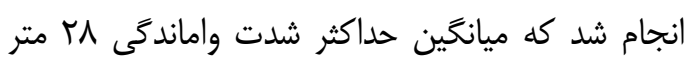

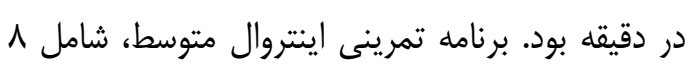

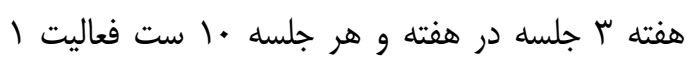

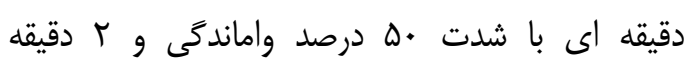

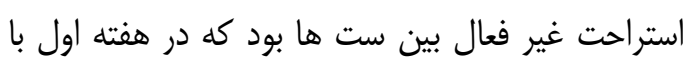

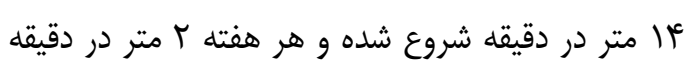

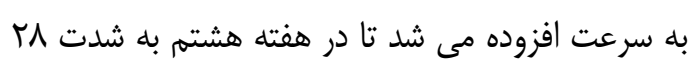

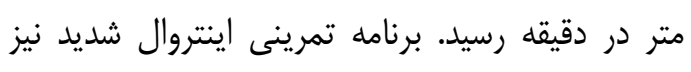

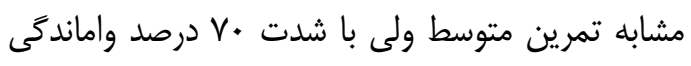

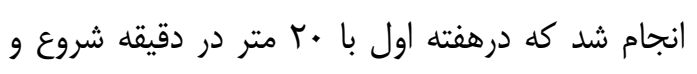

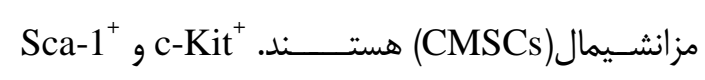

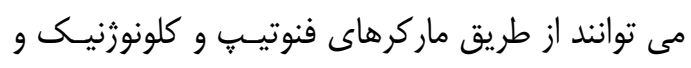

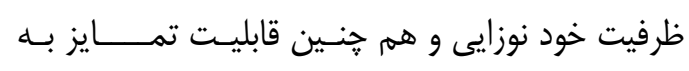

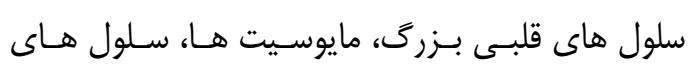
اندوتليال و سلول هاى عضله صاف تبـــيل شـوند (آ).

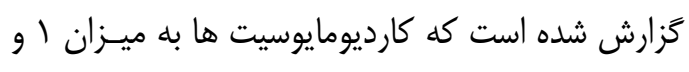

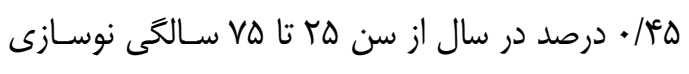

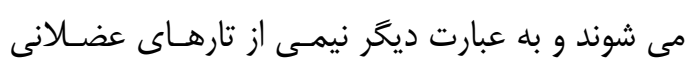

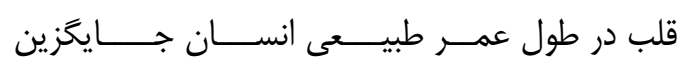

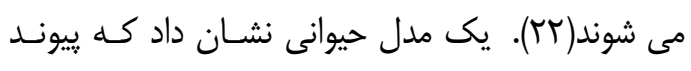

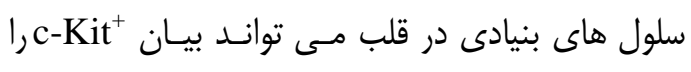

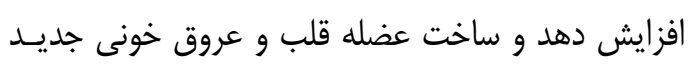

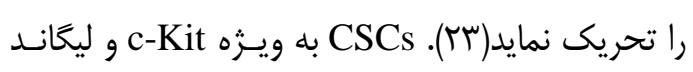

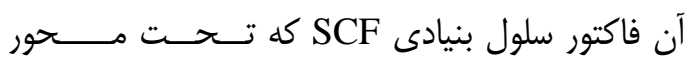

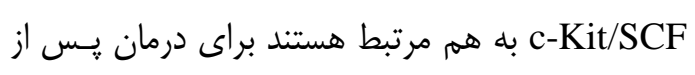

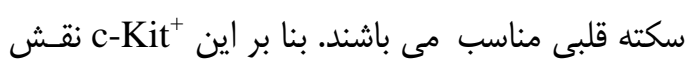

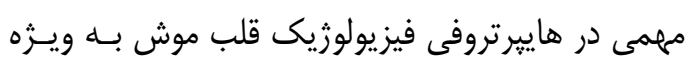

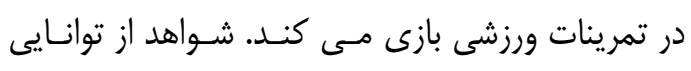

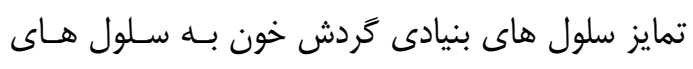

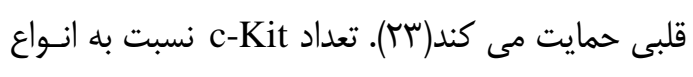

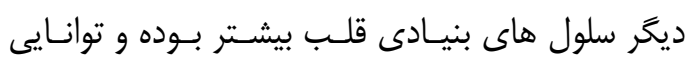

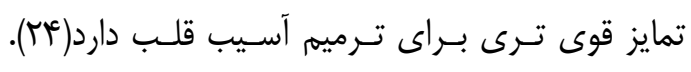
بررسى ها نشان مى دهد كه هاييرتروفى قلبى ناشـى از

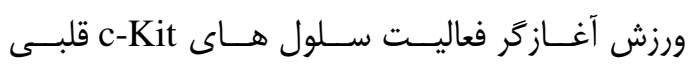

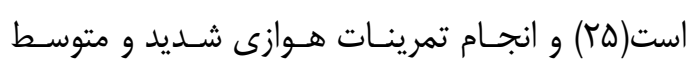

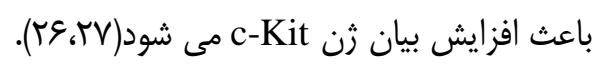

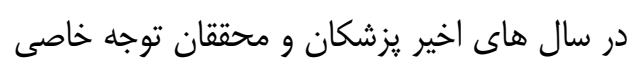

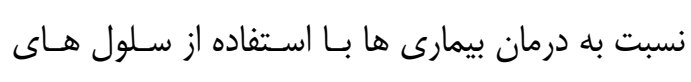

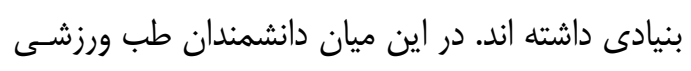

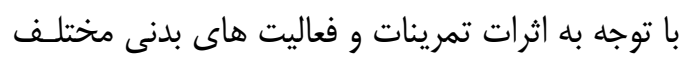

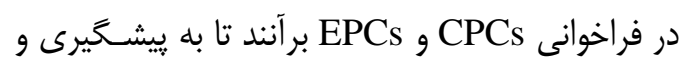
درمان بيمارى هاى مختلف قلبى-عروقى از اين طريق

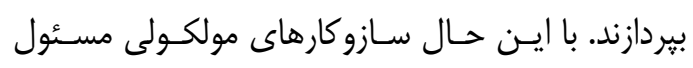
اثرات سودمند ورزش به طور كامل شناخته نشده است. با توجه به اهميت سلامت بافت قلب و اين كه مطالعات

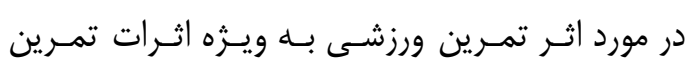
اينتروال با شدت هاى متفاوت بر سلول هاى بيش سـاز

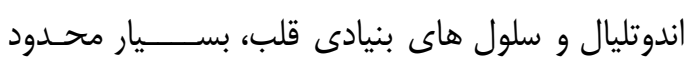




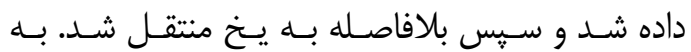

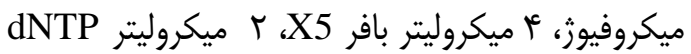

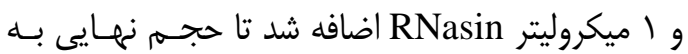

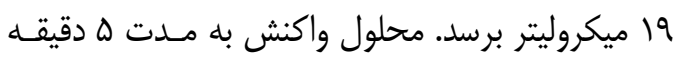
در Y د درجه سيلسيوس انكوبه شد. يك ميكروليتر آنزيم

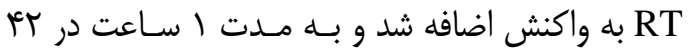

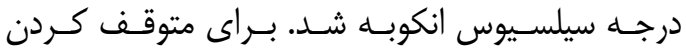

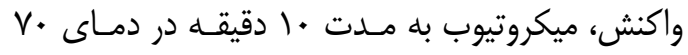

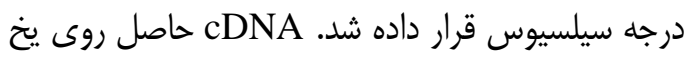

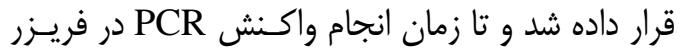

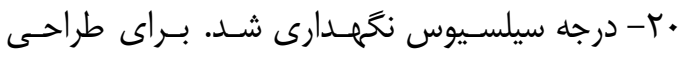

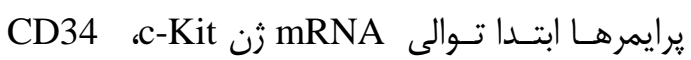

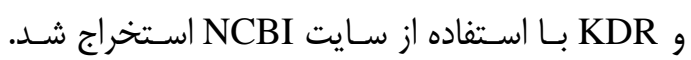
يرايمرها توسط نرم افزاركـامييوترى Allel ID سـاخته

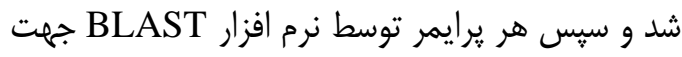

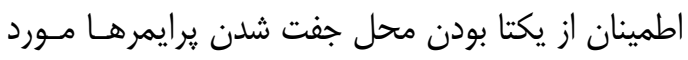

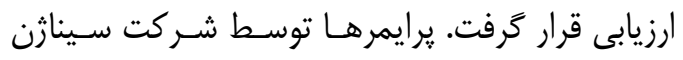
ساخته شد.

$$
\text { توالى بر/يمرها: }
$$

CD34 F CTTGGGAGCCACCAGAGCTATTC

CD34 R TTTCTCCTGTGGGACTCCAACTG

c-Kit F GCGCAAGCTTTTGTACAACTGAC

c-Kit R CCTAATCCCAGGGTTGTACACAG

KDR F ATGTAGCACGACAGAGACTGTGA

KDR R ACAGAGAACAAGGACACACTCAC

در اين تحقيق از ثن GAPDH به عنوان كنتـرل

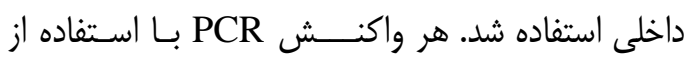
و PCR master mix (Applied Biosystems ABI Step One در دستخاه SYBR Green Detection (Applied Biosystems, Sequence Systems. Foster City, CA

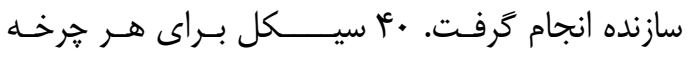
Real-time PCR سيكل شامل غو درجه سانتى كر اد براى ها ثانيـه، •ع

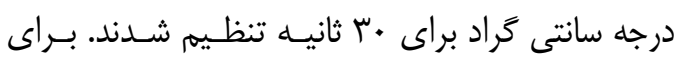

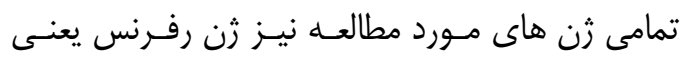
جAPDH Anneling جهت بررسى efficiency يرايمرها، منحنى اسـتاندارد

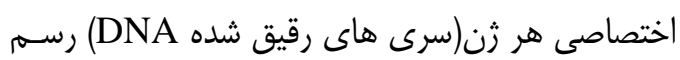

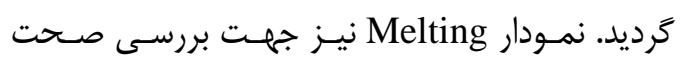

هر هفته r متر در دقيقه به سرعت افزوده شد تا در هفته هشتم به شدت عام متر در دقيقه رسيد. هم هنين

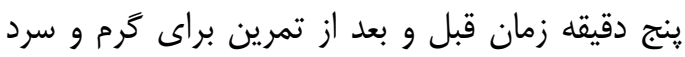

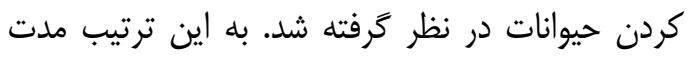

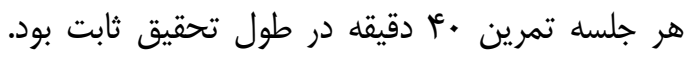
ست هاى فعاليت، مدت استراحت و شدت تمرين به به

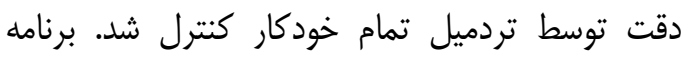

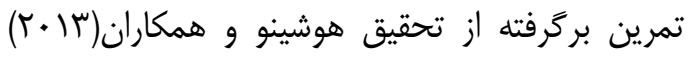

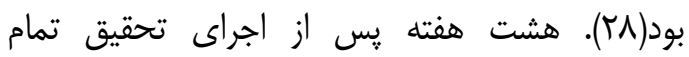

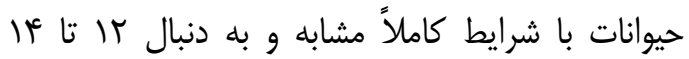

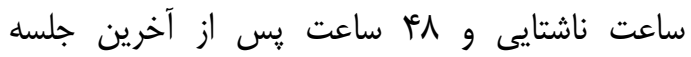

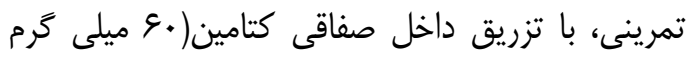

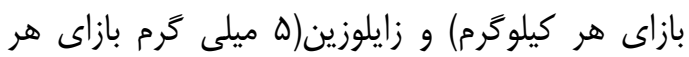

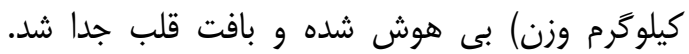

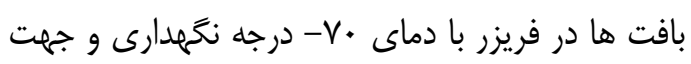

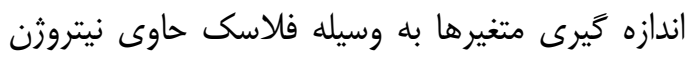
مايع به آزمايشكاه منتقل شد.

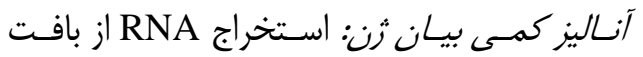

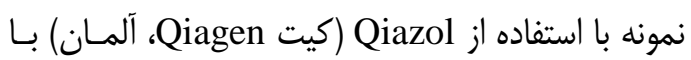

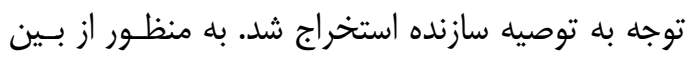

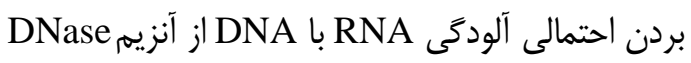

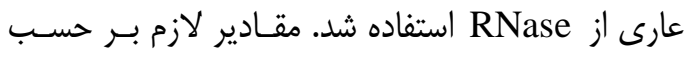
غلظت RNA استخراج شده تعيين شد. بدين ترتيب به

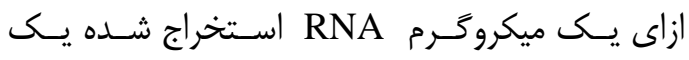

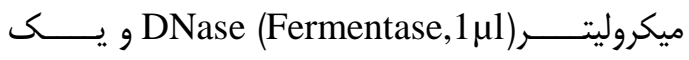

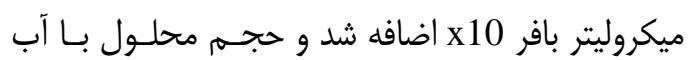

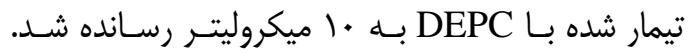

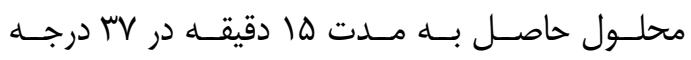

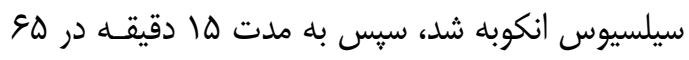
درجه سيلسيوس قرار داده شد تا آنزيم غير فــال شـود.

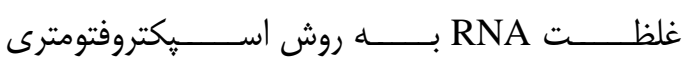
Eppendorff)UV

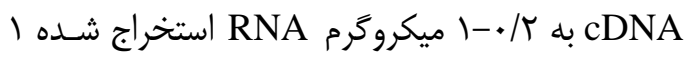
ميكروليتر Oligo dt اضافه شد. حجم نهايى اين مرحله

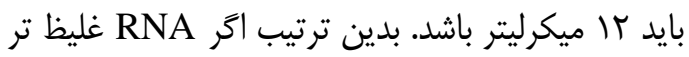
بود مقدار كمترى از آن برداشته شد با آب تيمار شده بـا بـا DEPC به حجم نهـايى rا ميكروليتـر رسـانده شـد. واكنش به مدت ه دقيقه در •V- درجه سيلسيوس قـرار 
وجود تفاوت بين سطوح c-Kit در كروه هـاى مختلـف يخوهش تاييد شد. نتايج آزمون تعقيبى شـفه نشـان داد داد

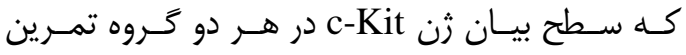

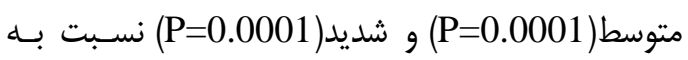
كروه كنترل افزايش معنـادارى دارد. و دركـروه تمـرين

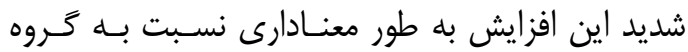

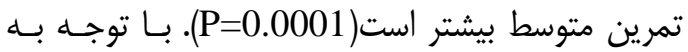

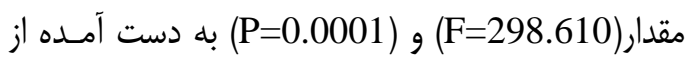
آزمون تحليل واريانس يك طرفه متغير CD34، آزمون

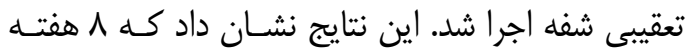
تمرين هوازى ايتتروال با شدت متوسط(P=0.0001) و شديد(P=0.0001) موجب افزايش معنادار سـطح بيـان

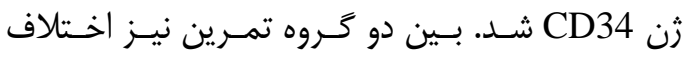
معنادارى مشاهده شد و سطح بيـان زن ايـن متغيــر در درد تمرين شديد به طور معنادارى بيشتر بـود (P=0.0001).

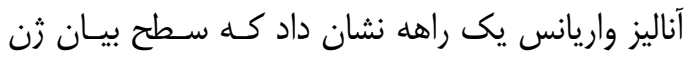

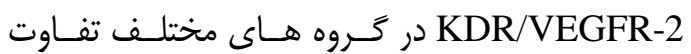

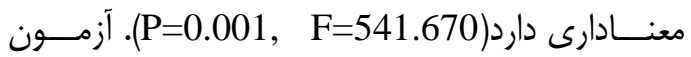
تعقيبـى شـفه در مـورد متغيـر KDR نشـان داد كـهـ

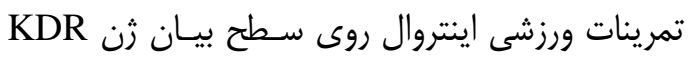

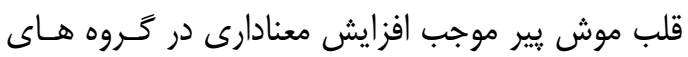

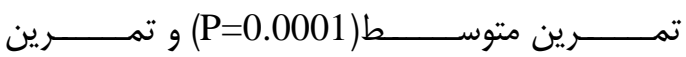
شديد(P=0.0001) شد. اين افـزايش در خـروه تمـرين

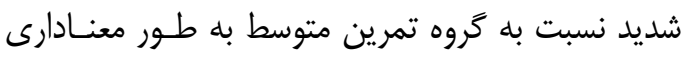

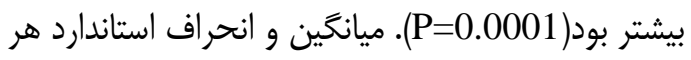
سه متغير در جدول شماره ال ارائه شده است.
واكنش هاى PCR انجام شده بـه صـورت اختصاصى

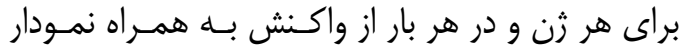

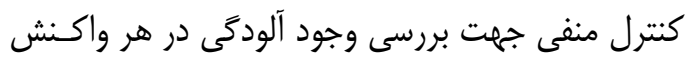

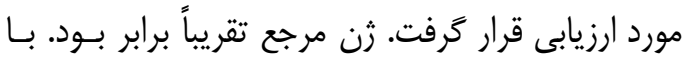

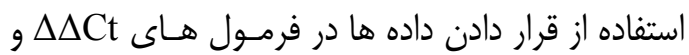
$\Delta \Delta \mathrm{Ct}-\mathrm{C}$

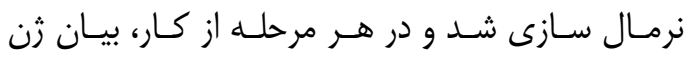

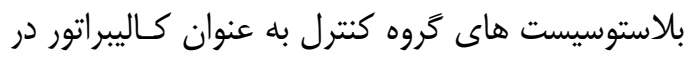
نظر كرفته شد.

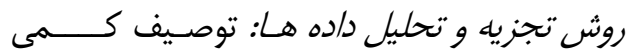

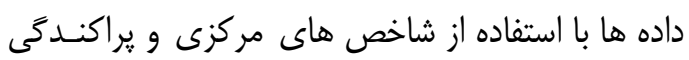

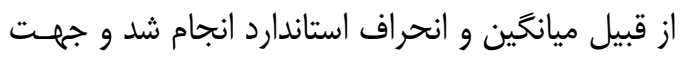
تعيين نرمال بودن توزيع داده ها از آزمون شـاييروويلك أنجان

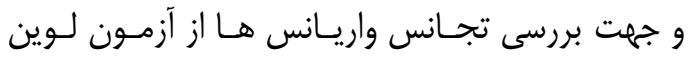

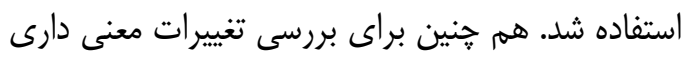

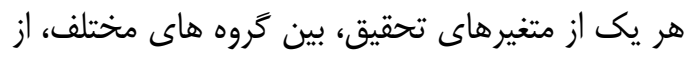

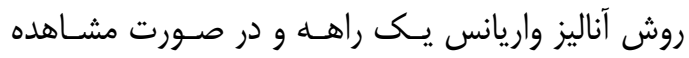
تفاوت معنى دار آمارى از آزمـون تعقيبـى شـفه جهـت

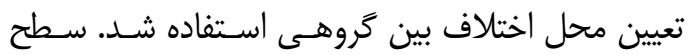

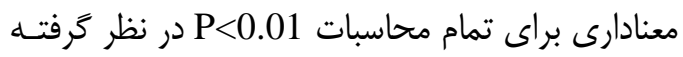

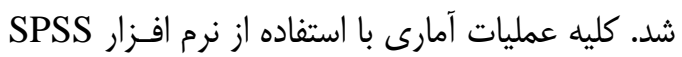
نسخه r انجام شد.

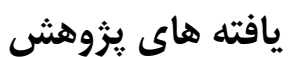

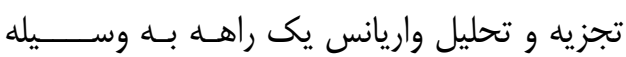

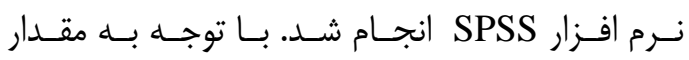

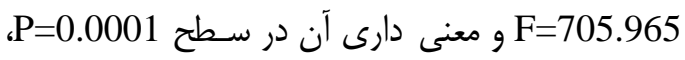

جدول شماره (. ميانكَين و انحراف استاندارد بيان زن KDR و CD34، C-Kit در ترووه هاى مختلف تحقيق

\begin{tabular}{|c|c|c|c|}
\hline متغيرها & كنترل & تمرين متوسط & تمرين شديد \\
\hline CD34 & $.1 .4 t \pm .1 .19$ & $. / 1 W \pm \pm . / .19 \%$ & 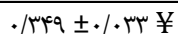 \\
\hline KDR & $. / . \mu q \pm . / .1 r$ & $\cdot / T \Delta T^{\top} \pm \cdot / \cdot T \Delta *$ & . \\
\hline c-Kit & س.././. & $. / 1 V^{\mu} \pm \cdot / \cdot r \cdot * *$ &.$/$ rqV.$\pm / . . q ¥$ \\
\hline
\end{tabular}

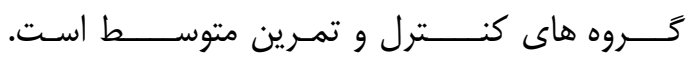

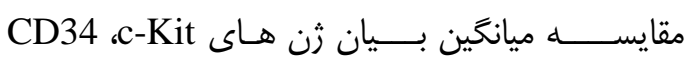

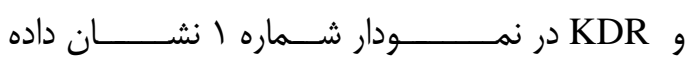
شـــــده است.
داده هاى جـدول شـماره ا نشـان مـى دهـــ كـهـ

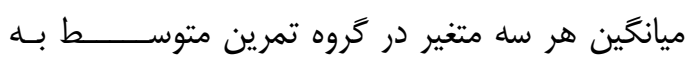

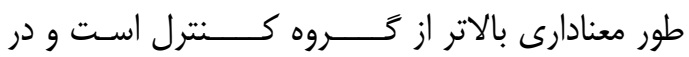

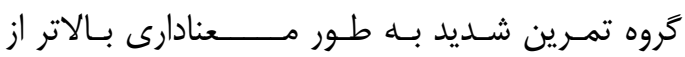




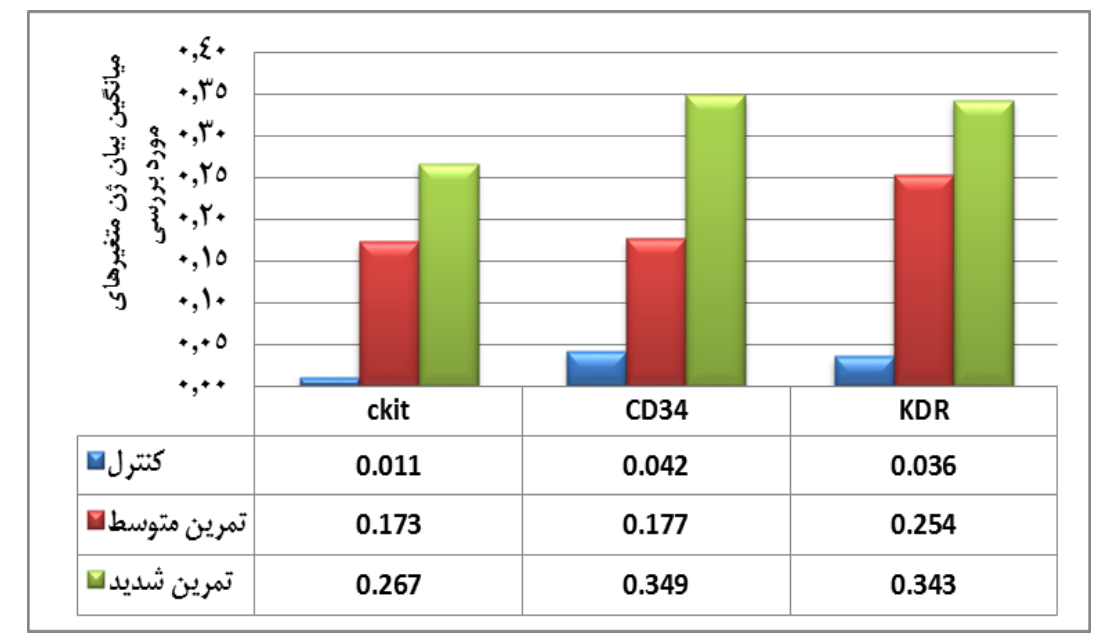

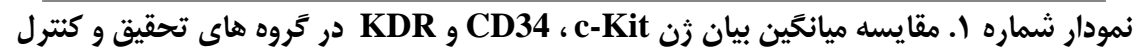

تمـرين ورزشـى بــه طـور بـالقوه بــهـ كـاهش اسـترس

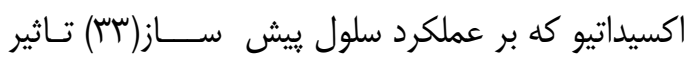
مى كذارد و كاهش قندخون ناشتا، مربوط است. ظرفي تشكيل عروق به وسيله EPCs در غلظت بالاى كلوكز مختل مى شود( ع آس).

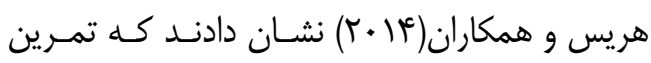

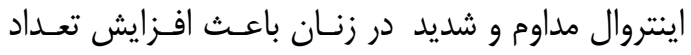

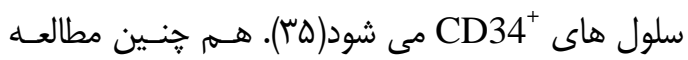

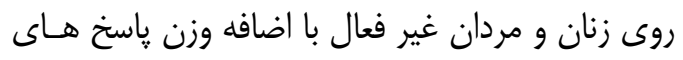

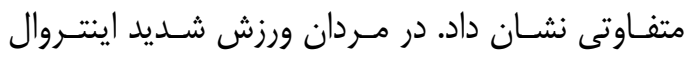
ميزان سلول هاى اندوتليال را كـاهش داد امـا در زنـان

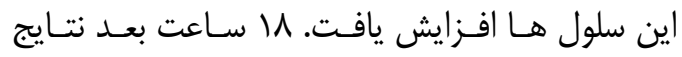

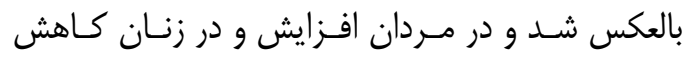

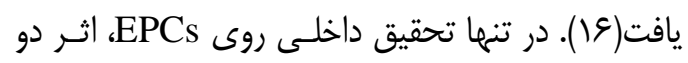

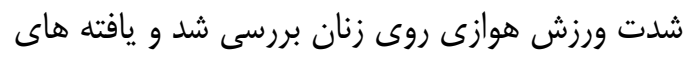

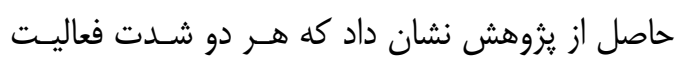
بدنى متوسـط و شـديد باعـث افـزايش معنــادار تعـداد CD34

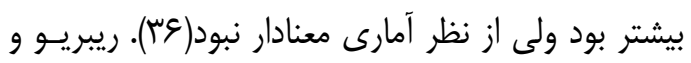

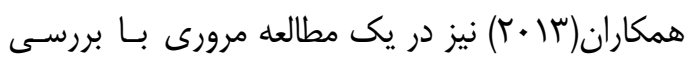

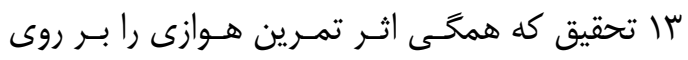
بيماران قلبى آزمايش كرده بودند، به اين نتيجه رئه رسيدند

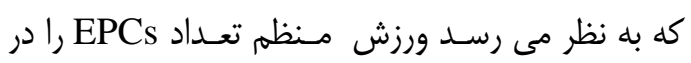

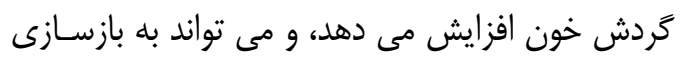

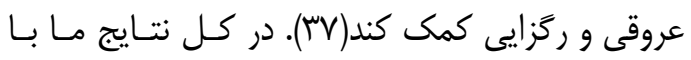

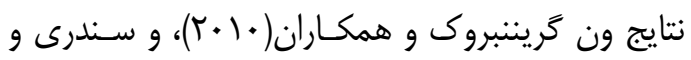

با توجه به اين شكل در هر سه متغير بين دو گروه تمرين متوسط و تمرين شديد با كروه كنترل اختلاف

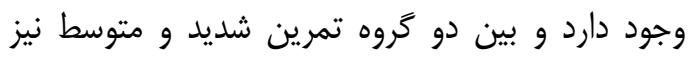
تفاوت معنادار است. بحث و نتيجه كيرى مطالعه حاضر نشان داد كه تمرينات مـنظهم اينتـروال

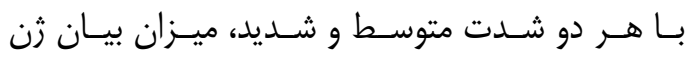

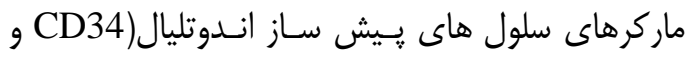

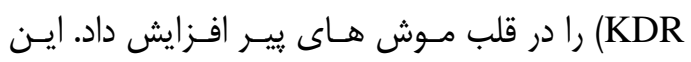

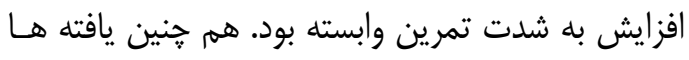

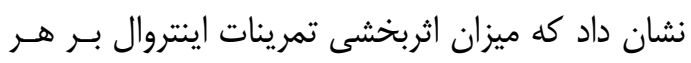

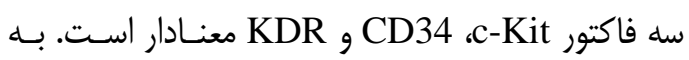
حدى كه تمرينات متوسط و شديد سطح بيـان ثن هـر

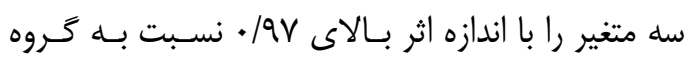
كنترل افزايش دادند. اين تحقيق نشان داد كـهـ تمــرين

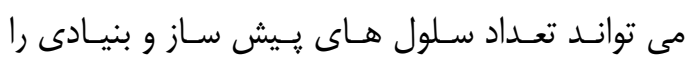

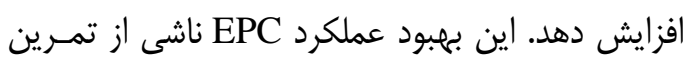

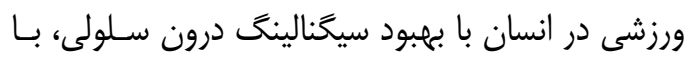

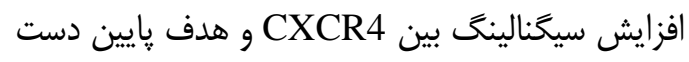

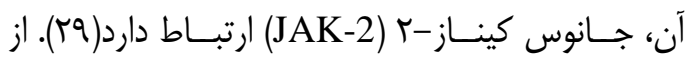

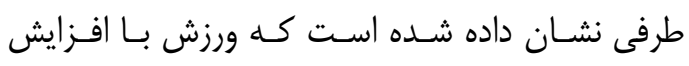

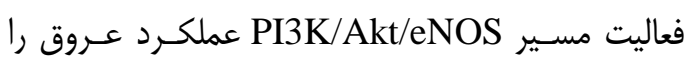
بهبود مى دهد •ب). اين مسير نقش محورى در حركت EPCs

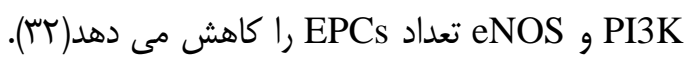

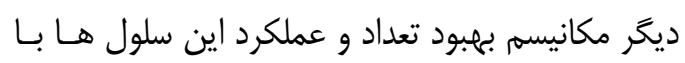


بررسى ها نشان داد با هفته تمرين شنا روى موش ها باعث هاييرتروفى معنادار قلب شده و دانسيته مـويركى

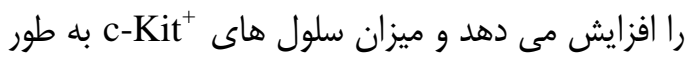

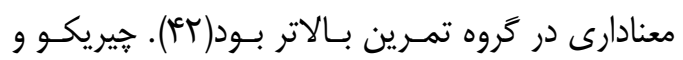

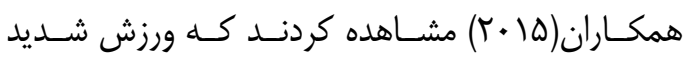
هوازى نكمهدارى سلول هاى مشتق از مغز استختوان را

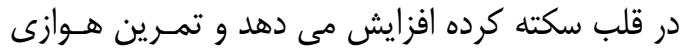

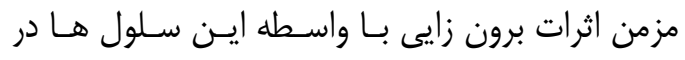

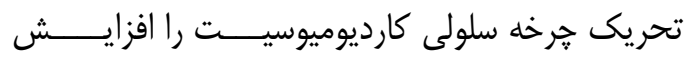
مى دهد. اين نتايج نشان مى دهـــ كـه ورزش ممكـن

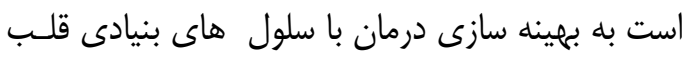

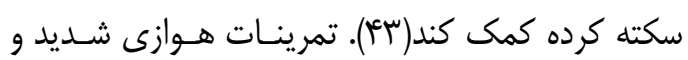

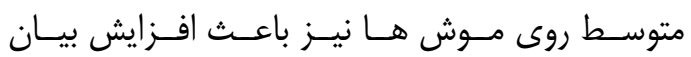
فاكتورهاى رونويسى c-Kit شد. اين ساز كارى به مدت

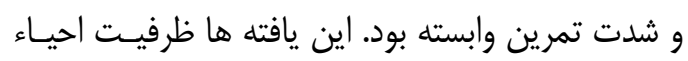

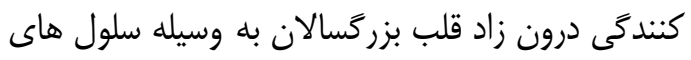

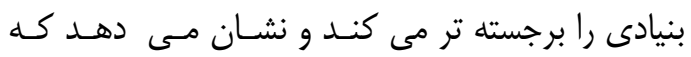

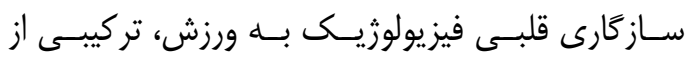

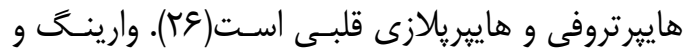

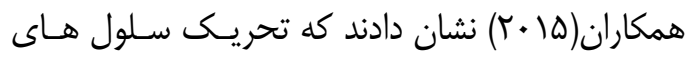

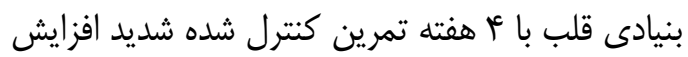

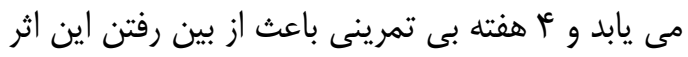
مى شود(TV). كزارش شده است كه تمرين ورزشى در

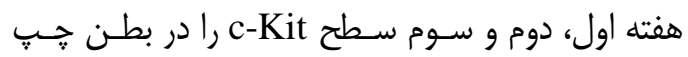
موش بيان مى كند ولى افزايش در بطن راست در هفته

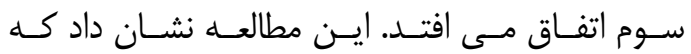

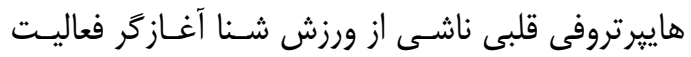

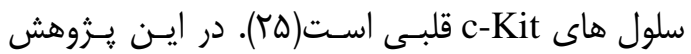

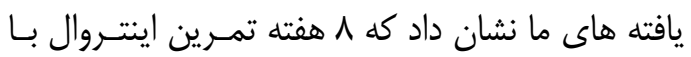

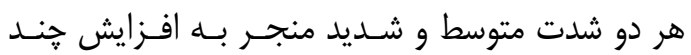

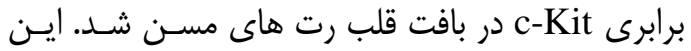

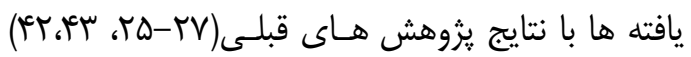
همسو بود. با اين تفاوت كه مطالعات قبلى اثر تمرينـات

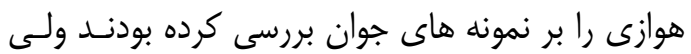

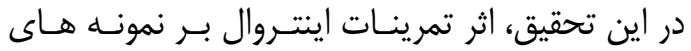
مسن بررسى شد. هم جنين اثر شدت تمـرين اينتـروال

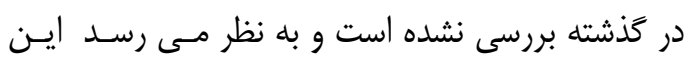

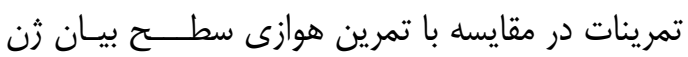

همكاران(1) (Y)، كه افزايش تعداد و عملكرد EPCs در ورزش هوازى شديد گزارش كرده بودند همسو بود ولى هلى

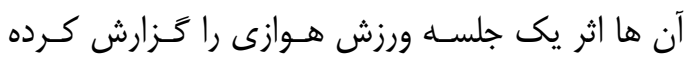

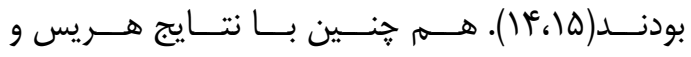

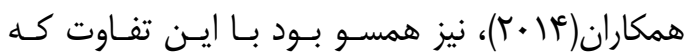

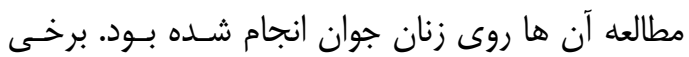

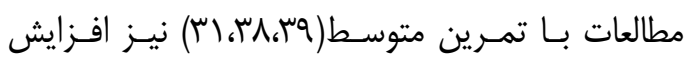

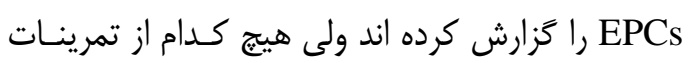

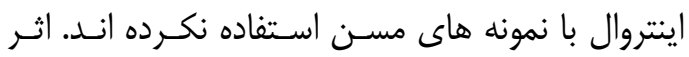
شدت تمرين بر EPCs به ويزه در سالمندان در كذشته

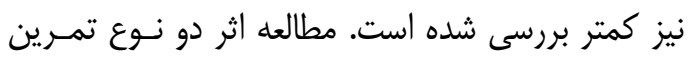

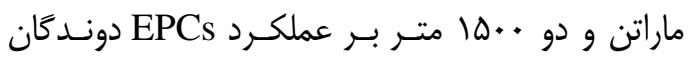

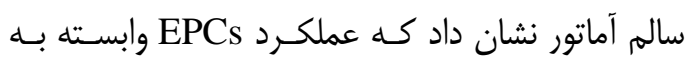

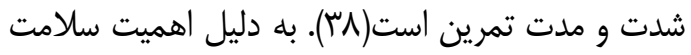
قلب در اين يزوهش اثر يك برنامه تمرينى اينتروال بــر

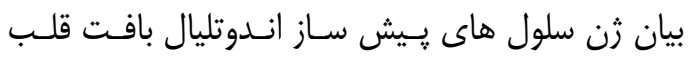
بررسى شد و وجه تمايز اين تحقيق بررسى اثر اين نوع سئ سان

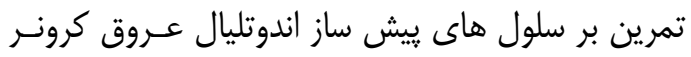

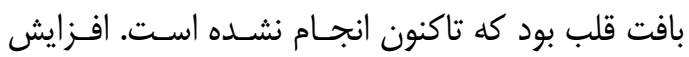

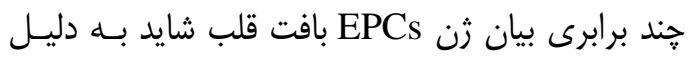
نوع تمرين باشد ولى به تحقيقات بيشترى در اين زمينه

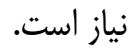
يثزوهش حاضر نشان داد كه تمرينات منظم اينتـروال

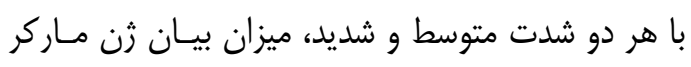

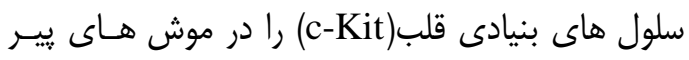
افزايش داد. اين افزايش به شدت تمـرين وابسـته بـود.

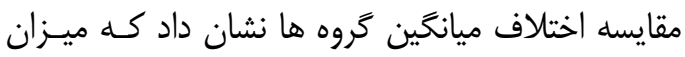

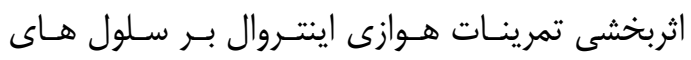

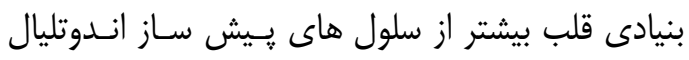

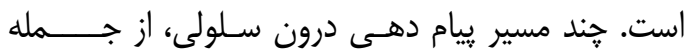

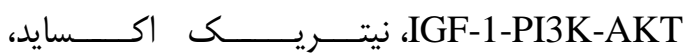

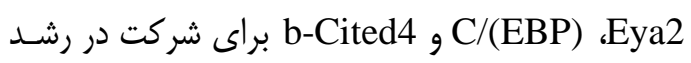

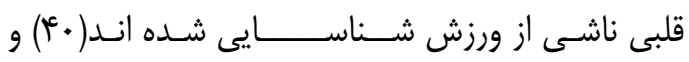
SDF- و SDF-1/CXCR7/AKT

CSCs نقش مهمى در مهـاجرت 1/CXCR4/ERK

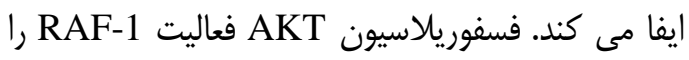

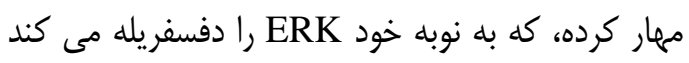
و موجب تنظيم منفى مهاجرت CSCs مـى شـود (أ). 
شده است. و اين تغييرات سلولى مفيد وابسته به شـدت

ورزش باعث افزايش توده عضلانى انقباضسى و كـاهش

فشار ديواره قلب و در نتيجه بهبود عملكرد قلـب شـده

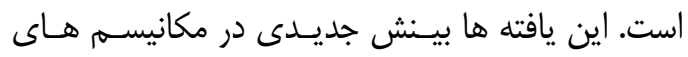

مولكولى دخيل در ياسـخ هييرتروفيـك و احيـاء كنتــده

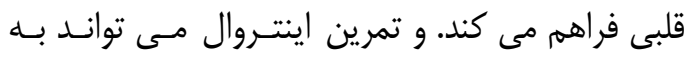

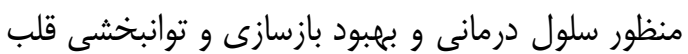

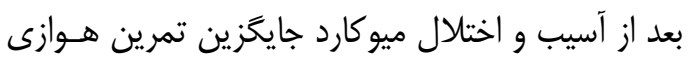

شود.

\section{References}

1.Wang H, Listrat A, Meunier B, Gueugneau M, Coudy C, Combaret L, et al. Apoptosis in capillary endothelial cells in ageing skeletal muscle. Aging Cell 2014;13:254-62. doi: 10.1111/acel.12169

2.Soucy KG, Ryoo S, Benjo A, Lim HK, Gupta G, Sohi JS, et al. Impaired shear stress induced nitric oxide production through decreased NOS phosphorylation contributes to age related vascular stiffness. J Appl Physiol 2006;101:1751-9. doi:10.1152/japplphysiol.00138.2006

3. Dignat F, Sampol J. Circulating endothelial cells in vascular disorders: new insights into an old concept. Euro J Haematol 2000; 65:215-20. doi:10.1034/j.1600-0609.2000.065004215.x 4. Farzanegi P, Amanzadeh MA. [Effect of aerobic exercise on endothelin-1 C- reactive protein and nitric oxside in hypertensive postmenopausal women]. RJ Med Sci 2014; 21:27-35. (Persian)

5. Ross MD, Malone E, Florida G. Vascular ageing and exercise focus on cellular reparative processes. Oxid Med Cell Longev 2016; 35:83956. doi: 10.1155/2016/3583956.

6. Hristov M, Erl W, Weber PC. Endothelial progenitor cells mobilization differentiation and homing. Arterioscler Thromb Vasc Biol 2003; 23:1185-9. doi:10.1161/01.ATV.0000073832.49290.B 5.

7. Kocher AA, Schuster MD, Szabolcs MJ, Takuma S, Burkhoff D, Wang J, et al. Neovascularization of ischemic myocardium by human bone marrow derived angioblasts prevents cardiomyocyte

$$
\begin{aligned}
& \text { c-Kit را بيشتر افزايش مى دهد. البته در اين مورد بــه } \\
& \text { تحقيقات بيشترى نياز است كه اثر انواع مختلف تمرين } \\
& \text { را بررسى نمايند. } \\
& \text { يافته ها نشان داد، تمرينـات مـنظم اينتـروال بــا دو } \\
& \text { شدت متفاوت سطح بيان زن عامل ساخت سلول هـاى دئن } \\
& \text { قلبى و عوامل رگزايى را در نمونه هاى سالمند افـزايش }
\end{aligned}
$$

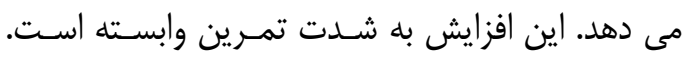

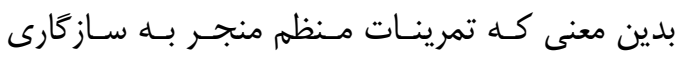

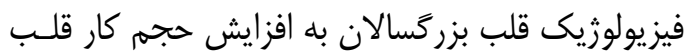

apoptosis reduces remodeling and improves cardiac function. Nat Med 2001; 7:430-6.

8.Zhang ZG, Zhang L, Jiang Q, Chopp M. Bone marrow derived endothelial progenitor cells participate in cerebral neovascularization after focal cerebral ischemia in the adult mouse. Circ Res 2002; 90:284-8. doi: 10.1161/hh0302.104460

9.Harrison JS, Rameshwar P, Chang V, Bandari P. Oxygen saturation in the bone marrow of healthy volunteers. Blood 2002; 1; 99:394.

10.Ceradini DJ, Kulkarni AR, Callaghan MJ, Tepper OM, Bastidas N, Kleinman $\mathrm{ME}$, et al. Progenitor cell trafficking is regulated by hypoxic gradients through HIF-1 induction of SDF-1. Nat Med 2004; 10:858-64. doi: 10.1038/nm1075

11. Bahrani S, Javanmard SH, Mortazavi ZS, Motamer M, Esfahani FN. [Effects of testosterone on the number of circulating endothelial progenitor cells in wistar Rats]. J Isfahan Med Sch 2012; 30:1329-35. (Persian)

12.Sandri M, Viehmann M, Adams V, Rabald K, Mangner N, Hollriegel R, et al. Chronic heart failure and aging effects of exercise training on endothelial function and mechanisms of endothelial regeneration results from the leipzig exercise intervention in chronic heart failure and aging study. Eur J Prev Cardiol 2016; 23:349-58.

doi: $10.1177 / 2047487315588391$.

13. Wang Y, Cao Q, Wangetal F. SIRT1protects against oxidative stress induced endothelial progenitor cells apoptosis by inhibit ing FOXO3a via FOXO3a ubiquitination and degradation. $\mathrm{J}$ 
Cell Physiol 2015; 230:2098-107. doi: 10.1002/jcp.24938.

14. Craenenbroeck EM, Beckers PJ, Possemiers NM. Exercise acutely reverses dysfunction of circulating angiogenic cells in chronic heart failure. Euro Heart J 2010; 31:1924-34. doi: 10.1093/eurheartj/ehq058. 15.Sandri M, Bernhardbeck E, Adams V, Gielen S, Lenk K, Hollriegel R, et al. Maximal exercise limb ischemia and endothelial progenitor cells. European J Cardio Preve Rehabil 2011; 18:55-64. doi: 10.1097/HJR.0b013e32833ba654.

16.Durrer C, Robinson E, Wan Z, Martinez $\mathrm{N}$, Hummel ML, Jenkins NT, et al. Differential impact of acute high intensity exercise on circulating endothelial microparticles and insulin resistance between overweight obese males and females. Plos One 2015;10:115860. doi: 10.1371/journal.pone.0115860.

17.Bearzi C, Rota M, Hosoda T, Tillmanns J, Nascimbene A, De Angelis A, et al. Human cardiac stem cells. Proc Natl Acad Sci USA 2007; 104:14068-73. doi: 10.1073/pnas.0706760104.

18. Lyman SD, Jacobsen SE. C-kit ligand and Flt3 ligand stem/progenitor cell factors with overlapping yet distinct activities. Blood 1998; 91:1101-34.

19.Kubo H, Jaleel N, Kumarapeli A, Berretta RM, Bratinov G, Shan X, et al. Increased cardiac myocyte progenitors in failing human hearts. Circulation 2008; 118:649-57. doi: 10.1161/Circulationaha .107.761031.

20.Barile L, Messina E, Giacomello A, Marban E. Endogenous cardiac stem cells. Prog Cardio Dis 2007; 50:31- 48. doi:10.1016/j.pcad.2007.03.005.

21.Wang H, Chen H, Feng B, Wang X, He $\mathrm{X}, \mathrm{Hu} \mathrm{R}$, et al. Isolation and characterization of a Sca-1 +/CD31progenitor cell lineage derived from mouse heart tissue. BMC Biotechnol 2014; 14; 75. doi: 10.1186/1472-6750-14-75.

22. Bergmann O, Bhardwaj RD, Bernard S, Zdunek S, Barnabe $\mathrm{F}$, Walsh $\mathrm{S}$, et al. Evidence for cardiomyocyte renewal in humans. Science 2009; 324:98-102. doi: 10.1126/science. 1164680 .

23.Beltrami AP, Barlucchi L, Torella D, Baker M, Limana F, et al. Adult cardiac stem cells are multipotent and support myocardial regeneration. Cell 2003; 114:763-76.

24. Linke A, Muller P, Nurzynska D, Casarsa C, Torella D. Stem cells in the dog heart are self-renewing, clonogenic and multipotent and regenerate infarcted myocardium improving cardiac function. Proc Natl Sci USA 2005; 102:8966-71. doi: 10.1073/pnas.0502678102.

25. Junjie X, Tianzhao Xu, Jin Li, Dongcao Lv, Ping C, Qiulian Z, et al. Exercise induced physiological hypertrophy initiates activation of cardiac progenitor cells. Int $\mathbf{J}$ Clin Exp Pathol 2014; 7:663-9.

26. Waring CD, Vicinanza C, Papalamprou A, Smith A J. Purushothaman S, Goldspink $\mathrm{DF}$, et al. The adult heart responds to increased workload with physiologic hypertrophy cardiac stem cell activation and new myocyte formation. Eur Heart $\mathbf{J}$ 2012; 1-10. doi: 10.1093/eurheartj/ehs338.

27. Waring CD, Henning BJ, Smith AJ, Nadal B, Torella D, Ellison GM. Cardiac adaptations from 4 weeks of intensity controlled vigorous exercise are lost after a similar period of detraining. Physiol Rep 2015;3. doi: 10.14814/phy2.12302.

28.Hoshino D, Yoshida Y, Kitaoka Y, Hatta H, Bonen A. High intensity interval training increases intrinsic rates of mitochondrial fatty acid oxidation in Rat red and white skeletal muscle. Appl Physiol Nutr Metab 2013; 38:326-33. doi: 10.1139/apnm-2012-0257.

29.Xia WH, Li J, Su C, Yang Z, Chen L, $\mathrm{Wu} \mathrm{F}$, et al. Physical exercise attenuates age associated reduction in endothelium reparative capacity of endothelial progenitor cells by increasing CXCR4/JAK-2 signaling in healthy men. Aging Cell 2012; 11:111-9. doi: 10.1111/j.1474-9726.2011.00758.

30. Wang Y, Tian Z, Li Y, Chen S. Exercise training activations $\mathrm{PI} 3 \mathrm{~K} / \mathrm{Akt} / \mathrm{eNOS}$ signalling improves insulin resistance in post myocardial infarction Rats. FASEB J 2015; 29:993-4. doi: 10.14814/phy2.12339.

31.Chen X, Chen Q, Wang L, Li G. Ghrelin induces cell migration through GHSR1a mediated PI3K/Akt/eNOS/NO signaling pathway in endothelial progenitor cells. Metab Clin Exp 2013; 62:743-52. doi: 10.1016/j.metabol.2012.09.014. 
32. Xiao M, Men LN, Xu MG, Wang GB, Lv HT, Liu C. Berberine protects endothelial progenitor cell from damage of TNF-alpha via the PI3K/AKT/eNOS signaling pathway. European J Pharmacol 2014; 15:11-6. doi: 10.1016/j.ejphar.2014.09.024.

33. Wang Y, Cao Q, Wangetal F. SIRT1protects against oxidative stress induced endothelial progenitor cells apoptosis by inhibit-ing FOXO3a via FOXO3a ubiquitination and degradation. $\mathrm{J}$ Cell Physiol 2015; 230:2098-107. doi: 10.1002/jcp.24938.

34. Jiraritthamrong C, Kheolamai P, Pratya YU, Chayosumrit M, Supokawej A, Manochantr S, et al. Invitro vessel forming capacity of endothelial progenitor cells in high glucoseconditions. Ann Hematol2012; 91:311-20. doi: 10.1007/s00277-011-13006.

35. Harris E, Rakobowchuk M, Birch KM. Sprint interval and sprint continuous training increases circulating $\mathrm{CD} 34^{+}$cells and cardio respiratory fitness in young healthy women. Plos One 2014; 9: 108720. doi: 10.1371/journal.pone.0108720.

36. Khosravi N, Ravasi A, Sharifi F. [Effect of two different intensity of physical activity on circulating endothelial progenitor cells in healthy young Women]. Res Sport Med Technol 2012;1: 67-78. (Persian)

37. Ribeiro F, Ribeiro IP, Alves AJ, Monteiro M, Oliveira NL, Oliveira J, et al. Effects of exercise training on endothelial progenitor cells in cardiovascular disease: a systematic review. Am J Phys Med Rehabil 2013;92:1020-30. doi: 10.1097/PHM.0b013e31829b4c4f.
38.Bonsignore MR, Morici G, Riccioni R, Huertas A, Petrucci E, Veca M,et al. Hematopoietic and angiogenetic progenitors in healthy athletes different responses to endurance and maximal exercise. J Appl Physiol 2010; 109:60-7. doi: 10.1152/japplphysiol.01344.2009.

39. Schlager O, Giurgea A, Schuhfried O, Seidinger D, Hammer A, Groger M, et al. Exercise training increases endothelial progenitor cells and decreases asymmetric dimethylarginine in peripheral arterial disease a randomized controlled trial. Atherosclerosis 2011;217:240-8. doi: 10.1016/j.atherosclerosis. 2011.03.018.

40.Tao L, Bei Y, Zhang H, Xiao J, Li X. Exercise for the heart signaling pathways. Oncotarget 2015;6:20773-84. doi: 10.18632/oncotarget.4770.

41.Dong C, Yanli X, Ke Z, Ying W, Shiying $\mathrm{Z}$, Dong $\mathrm{K}$, et al. Crosstalk between SDF-1/CXCR4 and SDF$1 / C X C R 7$ in cardiac stem cell migration. Sci Rep 2015; 5:16813. doi: 10.1038/srep16813.

42. Leite CF, Lopes CS, Alves AC, Capitelli CS, Silva MV, Oliveira LF, et al. Endogenous resident c-kit cardiac stem cells increase in mice with an exercise induced physiologically hypertrophied heart. Stem Cell Res 2015; 15:151-64. doi: 10.1016/j.scr.2015.05.011.

43. Chirico EN, Ding D, Muthukumaran G, Houser SR, Starosta T, Mu A, et al. Acute aerobic exercise increases exogenously infused bone marrow cell retention in the heart. Physiol Rep 2015; 3:1-10. doi: 10.14814/phy2.12566. 


\title{
Effect of Interval Training Intensity on Gene Expression of Endothelial Progenitor Cells and Cardiac Stem Cells in Aged Rats
}

\author{
Shareef Rezaei ${ }^{1}$, Hasan Matinhomaee ${ }^{I^{*}},{ }_{\text {Mohammad Ali Azarbayjani }}{ }^{1}$, Parvin Farzanegi ${ }^{2}$
}

(Received: September 10, 2016

Accepted: February 6, 2017)

\begin{abstract}
Introduction: Aging is accompanied by anatomical and physiological changes in most tissues and organs, especially the reduction of cells, tissues, and vascular levels. Endothelial progenitor cells are involved in maintaining endothelial health, preventing endothelial dysfunction, and increasing neovascularization process. Cardiac stem cells are effective in the regeneration and repair of heart tissue. Regular exercise training increases both of these cells. We aimed to investigate the effect of eight weeks of moderate and intense interval training on gene expression of endothelial progenitor cells and cardiac stem cells in aged rats.
\end{abstract}

Materials and Methods: Twenty-one Wistar female rats with the mean age of $24 \pm 1$ months and the mean weight of $265 \pm 44 \mathrm{~g}$ were randomly divided into three groups of control $(n=7)$, moderate exercise $(n=7)$, and intense exercise $(n=7)$ groups. Both exercise groups were trained for 8 weeks, 3 sessions a week, each session for 40 minutes with 28 meters per minute in the moderate intensity exercise group and 34 meters per minute in the high intensity group. Forty-eight hours after the last training session, the rats were anesthetized and their cardiac tissue was isolated. CD34 and KDR gene expression for endothelial progenitor cells and c-Kit expression for cardiac stem cells were measured.
Findings: The results showed that the level of c-Kit gene expression in both groups of moderate $\quad(\mathrm{P}=0.0001)$ and intense $(\mathrm{P}=0.0001)$ training significantly increased compared to the control group. This increase was significantly higher in the intense training group $(\mathrm{P}=0.0001)$. Eight weeks of moderate interval training significantly increased the expression level of CD34 ( $\mathrm{P}=0.0001)$ and KDR $(\mathrm{P}=0.0001)$ genes. Also, eight weeks of high intensity interval training resulted in a significant increase in the level of gene expression of CD34 ( $\mathrm{P}=0.0001)$ and KDR $(\mathrm{P}=0.0001)$. This accumulative effect in the intense training group was significantly higher compared to the moderate group (CD34: $\mathrm{P}=0.0001$ and KDR: $\mathrm{P}=0.0001$ ).

Conclusion: The results of this study showed that regular interval training with two different intensity levels raises the level of gene expression of endothelial progenitor cells and cardiac stem cells. This increase is dependent on the intensity of training. High intensity interval training seems to stimulate the regeneration of heart tissue and development of coronary artery. These findings can be used to improve cell therapy and cardiac rehabilitation after injury and myocardial dysfunction, especially in the elderly.

Keywords: Moderate training, Highintensity training, endothelial progenitor cells, Cardiac stem cells, aging

1. Department of Sport Physiology, Central Tehran Branch, Islamic Azad University, Tehran, Iran

2. Department of Sport Physiology, Sari Branch, Islamic Azad University, Sari, Iran

* Correspondin author Email: hasanmatinhomaee@gmail.com 